Mobilising sustainable building assessment models: agents, strategies

\title{
and local effects
}

James Faulconbridge, Department of Organisation, Work and Technology, Lancaster University Management School, Lancaster University, Lancaster, LA1 4YX, UK

Email: ¡.faulconbridge@lancaster.ac.uk

Please cite as:

Faulconbridge JR (2015) Mobilising sustainable building assessment models: agents, strategies and local effects. Area 47 (2) 116-123 


\begin{abstract}
This paper considers how work on knowledge and policy mobilities can be used to analyse the processes behind and the local impacts of mobile sustainable building assessment models such as BREEAM and LEED. After reviewing existing concerns and critiques relating to the impacts of these models on the local sensitivity of sustainable building designs, consideration is given to the effects on local sensitivity of 'who mobilizes' the models, the 'intercity issues' associated with generating commensurability between places, and the way 'events along the way' are used to sell models. These questions reveal that work on knowledge and policy mobilities provides a useful framework through which to develop social science perspectives on the local impacts of mobile building assessment models. In particular, this approach highlights how processes of mobility are used to frame approaches to sustainable building design and potentially undermine attempts to render models sensitive to local challenges and solutions. It is, therefore, suggested that the knowledge and policy mobilities informed approach adopted here is beneficial as it places less emphasis on the intrinsic technical features of models and more emphasis on the powerful effects of processes of mobilisation on understandings and practices of sustainable design.
\end{abstract}

Keywords: Sustainable buildings; mobility; knowledge

\title{
Introduction
}

Buildings have become a central focus of national and transnational governance initiatives as well as industry strategies designed to tackle the causes of climate change 
and environmental degradation. The rationale for such a focus is hard to dispute. Around 40 per cent of all energy consumption occurs in buildings (Boschmann and Gabriel, 2013; Brown and Southworth, 2008), primarily through heating, cooling and lighting systems but also as a result of the various technologies, from computers to elevators, used as part of the everyday practices of occupants. Yet, attempts to reduce energy consumption in buildings and render them 'green' have caused significant controversy. In addition to concerns that the 'green' agenda too often squeezes out issues of social sustainability (Krueger and Agyeman, 2005), questions have been raised about the tendency to frame environmental sustainability in selective ways, writing some definitions in and others out (Guy and Moore, 2007), and to adopt universalist approaches that ignore local (vernacular) design solutions (Cole and Lorsch, 2003; Whitehead, 2007). Such accusations are particularly relevant to a set of mobile sustainable building assessment models.

Mobile sustainable building assessment models exist in various forms. They include the models deployed by global architecture and engineering firms (Faulconbridge, 2010, 2013; McNeill, 2008), and most notably a series of what might be termed 'private governance' initiatives - models such as the Building Research Establishment Environmental Assessment Model (BREEAM) and the Leadership in Energy and Environmental Design (LEED) being the most well-known. Other comparable schemes include the ASHRAE Green Guide, GreenCalc, Green Star, and GB Tool (for a summary of initiatives see Todd et al., 2001). Through such initiatives, standards for 'green' design and performance are set and policed by commercial organisations. Grading systems are used that reward features deemed to impact positively on levels of, amongst other things, energy and water consumption and waste production. 
Of interest here is the way that assessment models, through their international mobility, have opened-up or closed-down opportunities to use vernacular, local sustainability solutions. It is clear that sustainable building assessment models are now highly mobile. For example, the UK originating BREEAM has been used in over 50 countries to assess in total 250,000 buildings, with a further 1 million registered for certification (BREEAM, 2014). Meanwhile, the US LEED model is used in 135 countries and nearly 10,000 buildings have been or are registered to be assessed (USGBC, 2013a). The history of these models and their internationalisation has been reviewed extensively elsewhere (see for example Cidell, 2009a, 2009b; Sev, 2011; Wallhagen and Glaumann, 2011), revealing both an increasing commercialisation of the models (they are now major profit generators for their owners) and an ever growing geographical reach, in the case of BREEAM and LEED from Dubai to China, Poland to Portugal. Rather than mapping this geography and unpacking explanations of the presences and absences of each model from country-to-country (the various models have subtly different geographies), or exploring as much of the existing literature does the extent to which the technical features of models allow for local adaptations, this short paper outlines how work on knowledge and policy mobilities (McCann, 2011; Ward, 2006; Peck and Theodore, 2010) can enhance understanding of the local impacts of internationally mobile sustainable building assessment models.

Specifically, the paper draws on McCann's (2011) synthesis of work on knowledge and policy mobilities to reveal the way efforts to mobilise assessment models lead to the closing-down of opportunities to develop locally sensitive building designs. This draws 
attention to how, despite efforts to recognise vernacular design, the tactics deployed to mobilise models have governmental effects that (re)direct understandings of sustainability (Bulkeley, 2005, 2006) and constrain the ability of those using the models to adopt local design solutions. This has unintended consequences for energy consumption in buildings, with homogenising effects potentially negating the benefits gained from the deployment of a model and threatening to undermine claims of sustainability. It is suggested, therefore, that the issues elucidated by the knowledge and policy mobilities framing adopted in this paper should form the basis for geographically sensitive, critical social science analysis of the processes mobilising sustainable building assessment models and urban sustainability concepts more broadly.

\section{Sustainable building design: challenges and controversies}

Alongside a large technical literature that considers the different ways mobile sustainable building assessment models define and measure sustainability (e.g., Bunz et al., 2006; Reed et al., 2009), a growing body of work adopts a social science perspective to analyse the effects of assessment models. Ranging from studies exploring the potential for social inequity (Krueger and Agyeman, 2005), to critiques of the framing of sustainable building design in a way that eradicates pluralism and definitional debates (Guy and Moore, 2007), this literature opens-up space for contestations over sustainable building practices. In particular, this work draws attention to the need to consider whether mobile assessment models threaten to eradicate or at least undermine already existing, vernacular sustainable design practices (Cole and Lorsch, 2003; Whitehead, 2007). 
Concerns about the impacts of mobile sustainable building assessment models on vernacular (local) sustainable design have inspired geographers to make a series of important interventions. Through three related articles (Cidell, 2009a, 2009b; Cidell and Beata, 2009), Julie Cidell highlights how LEED has been used in the USA by an increasingly diverse array of building professionals and owners in more and more parts of the country. Importantly, though, it is also shown that the way the model is used in terms of the credits gained (and not gained) varies significantly from place-to-place; this indicating the importance of local sustainable design practice and raising questions about whether local nuances are given as much credit as they might be by the LEED model. Boschmann and Gabriel (2013) reach similar conclusions and argue that LEED rewards what they call 'light green' strategies, these being approaches that rely on generic technological fixes such as photo voltaics. Boschmann and Gabriel (2013) argue that by relying on 'light green' tactics, LEED does little to promote 'deep green' approaches, these being more localised solutions that generate, in particular, energy use reductions through designs and materials tailored to local environmental and building use characteristics.

Geographers' concerns about the local sensitivity of mobile sustainable building assessment models are echoed in a sub-set of architecture and construction literatures which highlight "a host of issues related to the use of assessment methods, including deployment and maintenance of proprietary assessment systems" (Cole, 2005: 457). For instance, Wallhagen and Glaumann (2011: 31) suggest that concerns exist because models "have different objectives and are often developed for different geographical contexts in places with different conditions and building cultures", something that means analysis is needed to identify the ways actors seek to adapt models to different 
local contexts. Similarly, Cole and Valdebenito (2013:2) suggest there are "important questions regarding the ways and extent that - without significant adaptation - they [models] can be meaningfully adopted by other countries". In the remainder of this paper I, therefore, consider how such issues can be elucidated, and in particular how the causes of the concerns highlighted in existing research unpicked, by channelling analysis through the lens of work on mobile knowledges and policies. I contend that when approached in this way it is possible to move beyond analysis of just the technical features of models, something that tends to dominate in existing work, for example through comparisons of the specifications of models and their ratings of buildings in different places. In particular, the knowledge and policy mobilities perspectives allows us to better understand the multiple effects of processes of mobilisation that inhibit the emergence of locally tailored, vernacular, and optimally effective sustainability solutions.

\section{Mobility tactics and their governmental effects}

In his analysis of the state of the art in research on policy and knowledge mobilities, McCann (2011) identifies three key strands of work that can help interpret the impacts of mobile sustainable building assessment models. Questions about 'who mobilizes policy' draw attention to the way that, far from being a natural phenomenon, mobility and its geography is the outcome of the strategic action of interested parties. In particular, the adoption of a Foucauldian perspective reveals how mobilizing agents are involved in the "specific representation of the world that is being created, maintained, aligned and made to count", this in turn "drawing attention to how the global is constituted through political rationalities and socio-technical practices which imagine 
and mobilise spaces and subjects in particular ways" (Larner, 2007: 332-333). The significance of this governmentality perspective is that it renders visible the kinds of framing work involved in mobilising models, such work inevitably opening-up certain ways of thinking about sustainability (or any other urban issue) whilst also closingdown others (Guy and Moore, 2007). Peck (2011) suggests this involves the production of ideological understandings, something that ultimately involves definition of the 'right' lessons and sources of knowledge (Peck and Theodore, 2010). The key message here, then, is that understanding why and by whom sustainable building design models are mobilised is crucial to understand the governmental processes at work which effect definitions and understandings of sustainability.

Analysis of 'intercity issues' draws attention to the forms of spatial imaginary that lead to distinctive geographical patterns of mobility. The existing literature is replete with examples of how such an imaginary is constructed, including through the use of benchmarking (Larner and Le Heron, 2004) and strategies that seek to make cities comparable and logical counterparts (Ward, 2006). As such, the geographies of mobility are said to be produced by constitutive work that opens up spaces of flow which serve the purposes of the interested parties mobilising the models (Peck, 2011). This implies that the mobility of models between their home-countries and other cities worldwide is not necessarily because of similarities between locations in terms of sustainable building design challenges or solutions. Rather, those seeking to mobilise the models generate an imaginary that suggests the receiving city or country will benefit from the model in question. This does not mean differences between the two locations are denied. Rather, mobility itself is framed as beneficial, difference between the locations being something to recognise but not prevent mobility. This can involve convincing 
"actors in once city that their place is commensurate with another" (McCann, 2011:

115). Research needs, therefore, to look for the effects of techniques designed to generate commensurability, this relating to the third strand of work that McCann (2011) highlights.

Analysis of 'events along the way' focuses attention on how the very means of mobilisation - whether it be a report, presentation, conference or study visit - are crucial in the framing and imaginary construction processes highlighted above. As such, the events, their locations and the work done at them open up spaces of mobility and determine where the model travels to. For instance, through ethnography of training workshops associated with microfinance models, Roy (2012) reveals how discourses, opinions, and images conveyed in presentations helped generate relational spaces of mobility. Hence Peck (2011) distinguishes between selling and telling, mobilisation for him involving the former more than the latter. This implies that understanding how models are sold through the means of mobilisation deployed, and how this selling deals with local difference, is crucial for understanding the impacts of mobile sustainable building assessment models. The way the models are packaged, presented and sold is, then, as important as their technical specifications because of the effects on the practices of those adopting the models in new locations. As McCann (2011: 118) notes, this means being attentive to how "Mobile policies are, then, shaped and given momentum in the telling of stories", this being the key process through which "Existing subjectivities and rationalities [are] remade" (Ward, 2006: 67). 
Temenos and McCann (2012: 1390) suggest that together analysis of 'who mobilizes', 'intercity issues' and 'events along the way' can help reveal how a 'sustainability fix' is produced to allow models such as BREEAM and LEED to take hold in new locations, this being "a spatially and historically contingent organization of economic interests, institutional capacities, and political positions". As such, the critical geographical perspective provided by the knowledge and policy mobilities literatures raises a series of questions about processes of mobilisation and their effects that existing literatures on sustainable building design models fail to fully address because of their tendency to focus on the technical features of models. Or, put another way, attention is drawn to how any benefits gained from the technical abilities of models to accommodate local design solutions are negated when processes of mobilisation frame understandings of sustainability in ways that devalue and write-out local ('deep green') design solutions in favour of generic global ('light green') approaches. Focussing on how mobility happens thus provides a potentially fruitful way of revealing hereto unconsidered factors affecting the local sensitivity of mobile sustainable building design models.

\section{Mobile sustainable building assessment models: examining influences on local} responsiveness

At first glance, concerns about the local insensitivity of mobile building assessment models might seem unfounded. At one level, the criteria set-out in models are relatively generic and have scope for local interpretation. For instance, Bunz et al. (2006: 40) note how statements relating to energy in LEED include "obtain 15-60\% energy savings over base case" and "use 5-20\% renewable energy sources, whilst in BREEAM statements include "use at least $10 \%$ of heat demand or electricity consumption from local 
renewable energy source" and "CO2 improvements of $15-100 \%$ over base case". In principle such criteria could be adhered to using a range of local design techniques and material/energy sources. At another level, BREEAM has national variants in the form of country specific schemes (for Germany, the Netherlands, Norway, Spain, and Sweden) and an international bespoke programme. LEED does not have national variants but does explicitly espouse the importance of local adaptation, the US Green Building Council (USGBC), the owner of the LEED model, noting on its website in 2013 when this article was written that:

"USGBC has developed Global Alternative Compliance Paths, options within LEED credits that make LEED more applicable for projects around the world. Taking this a step farther, USGBC is also developing Regional Alternative Compliance Paths. These options address different geographic and climactic regions while providing solutions to challenges faced by projects at a regional level. The first of these to be released are the Regional Alternative Compliance Paths for projects using LEED for Existing Buildings: Operations and Maintenance in Europe" (USGBC, 2013b).

Putting aside one obvious and not insignificant critique - that national variants appear misaligned with widespread recognition that situated building design is local or regional in character (Cole and Lorsch, 2003, Boschmann and Gabriel, 2013) - such model variants suggest some degree of local sensitivity. Indeed, one of Cidell and Beata's (2009) key findings was that there are variations in the credits accrued by LEED assessed buildings in different regions of the US, suggesting some ability to be responsive to local sustainability priorities. 
Perhaps, then, concerns about the local insensitivity of mobile sustainable building assessment models are unfounded? There are, however, indications in existing research that an over-reliance on technical analysis of differences between models, and on analysis of the way credit points have been accrued in buildings located in different locales, leads to the risk of missing some of the subtler ways that mobile models undermine vernacular forms of sustainable building design. This is particularly problematic when models are imported into starkly different international contexts, and not just different regions of the same country. Considering the questions the policy mobilities literature highlights in relation to 'who mobilizes', 'intercity issues', and 'events along the way' provides a means of revealing some of these subtler forms of local insensitivity.

In terms of 'who mobilizes', as Peck (2011) notes, mobility is always caught up in wider ideological projects. For building assessment models, the wider project of those mobilising the models is to both promote sustainability, and the model in questions as the preferred 'fix' (c.f., Temenos and McCann, 2012). Indeed, it has been widely noted (Burnett, 2007; Courtney, 1997) that because the organisations that own and mobilize models such as BREEAM and LEED ultimately need to make profits from the exporting of the models, tactics are driven first and foremost by an ambition to create a global brand, something that leads to consistency being as if not more important than local adaptability. For instance, in discussions of its alternative compliance paths, the LEED website in 2013 at the time of writing began with statements about how "global consistency" is a crucial principle of the LEED model. This "is the concept that no 
matter where in the world a LEED project is, it's certification means the same thing and represents the highest level of leadership" (USGBC, 2013b).

What becomes clear, then, is that when questions are asked about 'who mobilizes' the models, and about the motivations behind mobilization, a series of potential barriers emerge which threaten espoused and technically possible local adaptation. Particular representations of the sustainability challenge and the models in question, which emphasise the importance of 'best practice' and consistency in assessment, lead to the 'right' lessons (Peck and Theodore, 2010) promoted by mobilizers being lessons associated with global standards of 'light green' sustainable design. The power of such framings should not be underestimated. They draw on ideologies of global best practice that, as Bulkeley $(2005,2006)$ has shown, capture audiences, are hard to challenge, and ultimately influence the practice of those subjects targeted in ways which limit the possibility for local deviation from global standards (see also Ward, 2006).

Indeed, the 'intercity issues' frame of the mobilities literature draws our attention to the way the national schemes/regional compliance paths discussed act as relational tools designed to generate commensurability (McCann, 2011). National/local variants of a model act as means of constituting spaces of flow, difference being recognised but in ways that do not prevent mobility and the imposition of consistency. Hence national/local variants are means of benchmarking a city or country with others. By highlighting areas of consistency in terms of sustainability challenges and fixes, whilst acknowledging some local variability, it becomes possible to construct a sense of commensurability and the potential for mobility. The 'intercity issues' perspective 
suggests, in particular, that the disconnection of models from their home countries is ultimately impossible, but is disguised by efforts such as national/local variants that apparently take vernacular design issues seriously. The desire to minimise variations in how sustainability is approached so as to present the brand consistently leads to even national/local variants of a model being imprinted with definitions of sustainability developed in the models' home countries (Cole, 2005; Schweber, 2013).

Indeed, there is a significant body of evidence to suggest that the underlying desire for global consistency and the effects of mobilisation processes described above lead to less local variety in building design than might be expected. Boschmann and Gabriel (2013) note that only 15 points out of 241 in the six case study buildings they analysed were earned as a result of local design adaptations (what they call 'deep green' strategies). Meanwhile, Holmes and Hudson (2002) observe that in the case of BREEAM, materials rated by BRE (the parent company owning BREEAM) are usually used because of the need for particular types of data about their performance, this limiting opportunities for the incorporation of locally unique and sourced methods of cladding, insulation etc. Similarly, Sev (2011) argues that a disproportionately high amount of imported materials are used in buildings assessed by mobile models because of a lack of data on the energy performance of local (traditional) materials. This trend towards imported materials is in part driven by the product catalogues that accompany assessment models, such as the BRE Green Book and the ASHRAE Green Guide; these catalogues providing approved and rated 'best practice' materials which those designing and constructing buildings to be assessed by a mobile model are encouraged to use. 
Insights that a focus on 'events along the way' provides can help us further understand how such a paradoxical situation of local adaptation yet global consistency is rendered possible. For McCann (2011), 'events along the way', such as the promotional events, training workshops, conferences, supporting websites, and publicity materials, construct the kinds of governmentality highlighted by Larner (2007) and Peck (2011). As noted above, this governmentality involves controlling how issues of sustainability are conceived of, and in turn understandings of what is deemed appropriate as a 'fix' (Temenos and McCann, 2012). Schweber (2013) argues that in the case of BREEAM a penchant for consistency is rendered effective by such governmentality. As she notes, “the meaning of concepts such as 'sustainability' and 'green building' is not given...building professionals are busy giving content to these concepts on the ground" (Schweber, 2013: 130). Schweber highlights, in particular, how the global brands of mobile models come to represent sustainability in local contexts thanks to significant efforts on the part of those promoting the models. 'Events' are a key form of effort, being used to specify the way the brands define sustainable. The result is some knowledges and techniques of sustainability being rendered visible but others invisible, and identities being produced in terms of building designers, constructers and owners who come to understand and practice sustainability in ways defined by the models in question. As such, variations in the credits accrued by buildings in different local contexts do not necessarily indicate sensitivity to local sustainability issues. Local practices that are not valued and not credited and thus excluded from designs might be more important than the adaptations made within the constraints imposed by the definitions of sustainability in the models. 
The spreadsheets used to assess buildings, and which are used as part of training at 'events along the way', are particularly important tools in this process of rendering approaches to sustainability visible and invisible. For example, the main method of recording data about a building which is then used in BREEAM assessments is the 'tracker' sheet produced by approved assessors. This sheet acts as a means of selling (Peck, 2011) the model and constituting spaces of flow. It renders the ideas behind the model and their assessment criteria tangible and stable when applied in different local contexts thanks to the way the sheet locks-in and -out certain criteria. Specifically, the sheet identifies the credits to be achieved, and at the same time also obscures other approaches through their exclusion. As such the spreadsheet becomes a tool for defining at 'events along the way' what should (and by default what should not) be focussed upon, Schweber (2013) noting that in the case of BREEAM what is included tends to have originally made its way into sheets because of the demands of UK (model home country) building codes. The spreadsheet is, then, a 'technology' in Foucauldian terms which governs what is and is not a sustainability 'fix'.

Exemplifying the effects of such 'technologies', Wallhagen and Glaumann (2011) compared the rating of one building in Sweden using the US originating LEED, the Code for Sustainable Homes (a sister model to the UK originating BREEAM focussed on housing) and the local EcoEffect model. They point out that the three models all rated the same building differently, and awarded points for very different features based upon what was prioritised in the model in question. In particular, they note that the high proportion of energy sourced from the grid which is from renewables in Sweden was missed by the non-domestic mobile models. This led to LEED and Code for Sustainable Homes requiring an excessive and unnecessary focus on techniques to reduce energy 
use for a high score to be secured. Similar conclusions were reached by Kajikawa et al. (2011) who note that the effect of local insensitivity was 35\% of LEED rated buildings consuming more energy that their non-assessed counterparts. Capturing the ultimate cause of such paradoxes, and demonstrating the way, as Schweber (2013) claims, that 'technologies' such as the spreadsheet shape the identities and practices of building professionals, Reed et al. (2009: 8) describe how the effect of LEED has been to render “designers and owners...increasingly driven by scoring points and not designing sustainable buildings for a particular site and use; a phenomenon term[ed] 'LEED brain"”.

\section{Discussion and Conclusions}

The contribution of this brief exploratory paper is to outline how analyses through the lens of work on knowledge and policy mobilities can help elucidate some of the concerns expressed in existing research about the local sensitivity of sustainable building design models. It is argued that the approach adopted here is a useful way to deploy social scientific understanding to deal with the limitations of existing research whereby a focus on "comparison of the technical characteristics of methods" leads to a failure to recognise "equally important issues of context and application" (Cole, 2005: 457). In particular, the approach developed here brings into view the spectre of the mobility of sustainable building design models having detrimental effects that may outweigh any benefits gained. Specifically, the analysis here reveals that as a result of the priorities and interests of 'who mobilizes' the models in question, a series of 'intercity issues' that demand the generation of commensurability, and 'events along the way' designed to govern understandings and practices of sustainability, any positive 
effects of mobility might be eroded by a tendency to create homogenised approaches to sustainable building design. This conundrum emerges primarily as a result of the focus of those mobilising models on consistency, this driven by the desire to turn models into global brands and resulting in the use of 'technologies' that govern understandings of sustainability in ways that render the models legitimate global 'fixes' (Temenos and McCann, 2012). This search for global legitimacy risks, in particular, closing-down definitions of sustainability and reducing the pluralism needed for locally sensitive, vernacular solutions to be developed (Guy and Moore, 2007).

Table 1 further demonstrates the usefulness of the knowledge and policy mobilities frame. It outlines in relation to the case of one model - BREEAM - the kinds of questions that a focus on 'who mobilizes', 'intercity issues' and 'events along the way' opens-up, and the enhanced understanding of the causes of local (in)sensitivity such an approach can provide. Most important about table 1 is the way it highlights questions about the processes of mobilisation that affect the way a model is deployed in different contexts. This suggests future research needs to adopt a mobile methods approach that qualitatively traces the way interested parties render the models in question mobile. This approach necessitates interviews, observations (of 'events along the way' as well as the strategizing involved in developing mobilisation strategies), and the use of methods such as discourse analysis to critically interpret the documents promoting the models (for more on methodological implications see McCann, 2011; Roy, 2012).

[insert table 1 here] 
As such, the conceptual contribution of this short paper is to highlight the potential of the knowledge and policy mobilities framing to move research beyond a tendency to assess sensitivity to local/vernacular design through a focus on the technical features of mobile sustainable building assessment models and the number of locally specific credits achieved. Focussing on 'who mobilizes', 'intercity issues' and 'events along the way' allows the powerful effects of the processes of mobilisation to be revealed, these processes opening-up spaces of mobility by rendering places commensurable and the models' solutions to sustainability visible (and other solutions invisible). Such effects are fundamental to producing the outcomes that are observed in technical studies of models and buildings assessed by them. As such, the knowledge and policies mobilities approach provides a means of revealing the too often hidden processes that generate the outcomes that existing literatures on mobile sustainable building assessment models describe.

Of course, this paper only begins to explore the value of focussing upon questions of 'who mobilizes', 'intercity issues' and 'events along the way'. Table 1 outline how this focus might be transformed into an empirical research agenda. Much more detailed empirical scrutiny of models as they move and the situated impacts on specific buildings and cities is needed. There is, then, much exciting work to be done that brings to bear on questions of sustainability insights from policy and knowledge mobilities literatures.

\section{References}


Boschmann, E E \& Gabriel, J N 2013 Urban buesustainability and the LEED rating system: case studies on the role of regional characteristics and adaptive reuse in green building in Denver and Boulder, Colorado. The Geographical Journal.

BREEAM 2014 BREEAM in numbers. Available at http://www.breeam.org/page.jsp?id=559 [last accessed 26/08/2014]

Brown, M A \& Southworth, F 2008 Mitigating climate change through green buildings and smart growth. Environment and Planning A 40 653-75.

Bulkeley, H 2005 Reconfiguring environmental governance: towards a politics of scales and networks. Political geography. 24 875-902.

Bulkeley, H 2006 Urban sustainability: learning from best practice? Environment and Planning A 38 1029-44.

Bunz, K R, Henze, G P \& Tiller, D K 2006 Survey of sustainable building design practices in North America, Europe, and Asia. Journal of architectural engineering $1233-62$.

Burnett, J 2007 City buildings_-Eco-labels and shades of green! Landscape and urban planning 83 29-38.

Cidell, J 2009a Building green: The emerging geography of LEED-certified

buildings and professionals. Professional Geographer 61 200-15.

Cidell, J 2009b A political ecology of the built environment: LEED certification for green buildings. Local Environment 14 621-33.

Cidell, J \& Beata, A 2009 Spatial variation among green building certification categories: Does place matter? Landscape and urban planning 91 142-51.

Cole, R J 2005 Building environmental assessment methods: redefining intentions and roles. Building Research \& Information 33 455-67. 
Cole, R J \& Valdebenito, M J 2013 The importation of building environmental certification systems: international usages of BREEAM and LEED. Building Research \& Information 41 662-76.

Cole, R J \& Lorsch, R (Eds.) (2003) Buidlings, culture and Environment. Informing local and global practices, Oxford, Blackwell.

Courtney, R 1997 Building Research Establishment past, present and future. Building Research \& Information 25 285-91.

Eick, V 2012 The co-production of purified space: hybrid policing in German Business Improvement Districts. European urban and regional studies 19 121-36.

Faulconbridge, J R 2010 Global architects: learning and innovation through communities and constellations of practice. Environment and Planning A 42 284258.

Faulconbridge, J R 2013 Mobile 'green'design knowledge: institutions, bricolage and the relational production of embedded sustainable building designs. Transactions of the Institute of British Geographers.

Guy, S \& Moore, S 2007 Sustainable Architecture and the Pluralist Imagination. Journal of Architectural Education 60 15-23.

Holmes, J \& Hudson, G 2003 The application of BREEAM in corporate real estate: A case study in the design of a city centre office development. Journal of Corporate Real Estate 5 66-77.

Kajikawa, Y, Inoue, T \& Goh, T N 2011 Analysis of building environment assessment frameworks and their implications for sustainability indicators. Sustainability Science 6 233-46. 
Krueger, R \& Agyeman, J 2005 Sustainability schizophrenia or "actually existing sustainabilities?" toward a broader understanding of the politics and promise of local sustainability in the US. Geoforum 36 410-17.

Larner, W 2007 Expatriate experts and globalising governmentalities: the New Zealand diaspora strategy. Transactions of the Institute of British Geographers NS 32 $331-45$.

Larner, W \& Le Heron, R 2004 Global benchmarking: participating 'at a distance' in the globalizing economy. in Larner, W \& Walters, W eds Global Governmentality: Governing International Spaces. Routledge, London.

McCann, E J 2011 Urban policy mobilities and global circuits of knowledge: Toward a research agenda. Annals of the Association of American Geographers 101 107-30.

McNeill, D 2008 The global architect. Firms, fame and urban form Routledge, London $\&$ New York.

Peck J, 2011 Geographies of policy. From transfer-diffusion to mobility-mutation. Progress in Human Geography 35 773-797.

Peck, J \& Theodore, N 2010 Mobilizing policy: Models, methods, and mutations. Geoforum 41 169-74.

Reed, R, Bilos, A, Wilkinson, S \& Schulte, K-W 2009 International comparison of sustainable rating tools. The Journal of Sustainable Real Estate 1 1-22.

Roy, A 2012 Ethnographic circulations: space-time relations in the worlds of poverty management. Environment and Planning-Part A 4431.

Schweber, L 2013 The effect of BREEAM on clients and construction professionals. Building Research \& Information 41 129-45. 
Sev A 2011 A comparative analysis of building environmental assessment tools and suggestions for regional adaptations. Civil Engineering and Environmental Systems $28231-245$.

Todd, J A, Crawley, D, Geissler, S \& Lindsey, G 2001 Comparative assessment of environmental performance tools and the role of the Green Building Challenge. Building Research \& Information 29 324-35.

Temenos C, McCann E 2012 The local politics of policy mobility: learning, persuasion, and the production of a municipal sustainability fix. Environment and Planning A 44 1389-1406.

USGBC 2013a LEED. Available at http://new.usgbc.org/leed [last accessed $19 / 02 / 2013]$

USGBC 2013b Developing LEED. Available at http://new.usgbc.org/leed/developingleed [last accessed 19/02/2013]

Wallhagen M, Glaumann M 2011Design consequences of differences in building assessment tools: a case study. Building Research \& Information 39 16-33.

Ward, K 2011 Policies in motion and in place: the case of business improvement districts in McCann, E \& Ward, K eds Mobile urbanism: cities and policymaking in a global age. University of Minnesota Press, Minneapolis.

Ward, K 2006 'Policies in motion', urban management and state restructuring: the trans-local expansion of business improvement districts. International Journal of Urban and Regional Research 30 54-75.

Whitehead, M 2007 Spaces of sustainability: geographical perspectives on the sustainable society Routledge, London. 